\title{
PROBLEMS OF NARCISSISM IN EDUCATION: THE CULTURE OF NARCISSISM AS A DANGEROUS GLOBAL PHENOMENON FOR THE FUTURE
}

PROBLEMS

OF EDUCATION

IN THE $21^{\text {st }}$ CENTURY

Vol. 77, No. 4, 2019

489

\author{
Michal Podzimek \\ Technical University of Liberec, Czech Republic \\ E-mail: michal.podzimek@tul.cz
}

\begin{abstract}
Modernism, which appeared as a result of industrialization, has since then developed further, resulting in a postmodern society, characterized by a significant change in values. This shift in values is particularly evident in the quality of education, and man's subsequent relation towards work as a result. Schools have become social institutions in which learners spend their time in the role of served clients. The teacher is therefore assigned the social role of the servant, in which he is to primarily satisfy the pupil in his personal needs. This kind of relationship stems from the phenomenon of narcissism, which is already a cultural phenomenon. Studies of cultural narcissism are presented here, sampling relevant research of American provenience (with special focus on the USA). These studies suggest that cultural narcissism may become a global phenomenon in the future.

Keywords: cultural narcissism, contemporary individualism, narcissistic pathology, learning difficulties, pedagogical research.
\end{abstract}

\section{Introduction}

The late professor Christopher Lasch claimed that to liberate humanity from such outmoded ideas as love and duty has become the mission of Post-Freudian therapies, and particularly of their converts and popularizers (Lasch, 1980, p. 13). He labelled this pathological "liberation of humanity" the problem of narcissism: a form of self-absorption analogous to that of the mythological figure Narcissus. Professor Lasch was one of the firsts who attempted to grasp this topic as a social phenomenon and described it from a historical-anthropological perspective in a coherent way.

For the first time ever, Tom Wolfe covered this topic in his famous newspaper article in 1976, "The Me Decade and the Third Great Awakening." In like manner, in the 1980s, Lasch, in his influential monograph entitled The Culture of Narcissism, discussed narcissism as one of the manifestations of contemporary culture. In this work, narcissism was grasped for the first time as not simply a personality disorder in the psycho-pathological sense, but rather as a characteristic lifestyle of our current, hypermodern times (Lipovetsky, Hypermodern Times, 2005). In fact, this issue is discussed as a topic of popular science probably most intensively by Gilles Lipovetsky, who claimed already in 1983, in his first major publication entitled L'ère $d u$ vide: Essais sur l'individualisme contemporain that through personalization individualism changes into what could be called the culture of narcissism using the terminology of American sociology (Lipovetsky, 1983, p. 16).

The theme of cultural narcissism has therefore become urgent, especially during the last two decades with the so-called "Me, Me, Me Generation" (Stein, 2013), a term that shows a 
Michal PODZIMEK. Problems of narcissism in education: The culture of narcissism as a dangerous global phenomenon for the future

PROBLEMS

OF EDUCATION IN THE $21^{\text {st }}$ CENTURY Vol. 77, No. 4, 2019

further intensification of the issues of Tom Wolfe's (1976) “'Me' Decade." This generation, also frequently referred to as Millenials or Generation Y (Lyons, 2016), has grown up in the last two decades of the $20^{\text {th }}$ century, while the phenomenon itself can be shown to have continued in the generation of their children. Given the threat of cultural narcissism as an intensifying social phenomenon, people responsible for education and upbringing should logically be interested in this form of lifestyle. Since narcissism as a lifestyle and excessive narcissistic behavior in the sense of a psychological disorder are not mutually exclusive, but on the contrary, are overlapping phenomena which can constitute different phases of development of the trajectory of human life, it is necessary to approach this topic not only from a psychological, but also from a pedagogical point of view, drawing on pedagogical research. As it will be shown below, this is still a relatively "uncharted territory" both in sociological and pedagogical research. Nevertheless, some pioneering studies can be found, published during the first decade after the millennium in the United States, most typically in the form of research conducted by university lecturers and psychologists. This study is based on this research, even if one has to acknowledge that there are not many of them so far.

\section{Defining Narcissism}

The whole concept of the phenomenon of narcissism has developed naturally from psychology, respectively from the environment of Freudian psychoanalysis. Thus, at first, narcissism was defined as pathologic, more specifically as the psychological disorder of hedonists.

Yet, as this is generally known by professional psychologists, it is necessary to emphasize that the phenomenon of narcissism may not always be pathological. Sigmund Freud himself has distinguished in his work Totem und Tabu: Einige Übereinstimmungen im Seelenleben der Wilden und der Neurotiker two types of narcissism. The first one belongs to the natural development of children, who have to, at an early development stage of their personality, cope with the problem of self-centeredness besides hysteria. Only if the child does not resolve this problem by the end of the third year of his life does one talk of so-called secondary narcissism, which is, however, already considered pathological. In other words, being convinced of one's omnipotence during early childhood is a natural part of one's normal psychological development.

However, in order to avoid these attitudes becoming excessive, and thus pathological, children must gradually lose these beliefs, realizing that the objects of his narcissism are not dependent on him, on the contrary, the opposite is true. Freud also points out that even if one manages to cope with these facts of life normally in childhood, to some extent, one always remains somewhat narcissistic even in adulthood. This natural narcissism evokes the human will to learn to deal with self-centeredness (Freud, 1934).

Similarly to Sigmund Freud, Erich Fromm uses the term narcissism to refer to asocial individualism (Fromm, 1964, 52). He also takes into account the fact that narcissism has its important socio-biological function in the entire mentally healthy population by ensuring the fulfillment of individual desires, and it thus, paradoxically, helps to develop relationships through competitiveness. Therefore, in Fromm's view, narcissism is necessary for the quality, and sometimes for the very preservation, of life. Fromm nevertheless points out in his book, The Heart of Man: His Genius for Good and Evil, that narcissism can also be dangerous if it develops to a pathological form (Fromm, 1964). Fromm, in his historical analysis of some of the personalities of the past, does not hesitate to say that their excessive behavior was the result of the strong influence of a pathological narcissism: "From Caligula and Nero to Stalin and Hitler we see that their need to find believers, to transform reality so that it fits their narcissism, and to destroy all critics, is so intense and so desperate precisely because it is an attempt to prevent the outbreak of insanity" (62). 
What, however, is new in the contemporary understanding of narcissism, compared to Freud's psychoanalysis, is its perception as a group phenomenon: a so-called cultural narcissism. If, at the time of Freud, pathological narcissism was the phenomenon of only the minority population of the rich, today virtually the whole majority of Western society is permeated by it. In terms of Consumer society not only provides individuals, but also groups, with the opportunity to achieve a malignant type of narcissistic gratification in their pursuit to avoid dissatisfaction. In turn, for those who are economically and culturally too poor to participate in this pursuit, the only source of satisfaction, and often a very effective one, is their narcissistic pride in belonging to a group (Fromm, 1964, p. 89). In other words, the ancient Roman motto "panem et circenses" can be said to be resurrected, figuring among the leading phenomena of consumerism.

The area of cultural narcissism, as perceived by Erich Fromm or Zygmunt Bauman, as well as similar thinkers, such as Heinz Kohut, Otto Kernberg or Irvin Yalom, has been grasped in its full complexity professor Lasch, mentioned above, describing some of the main characteristics of narcissistic society in his introduction to his book, The Culture of Narcissism: American Life in an Age of Diminishing Expectations. These are:

- a general loss of historical continuity (indifference to the past and the future);

- dependence on bureaucracy;

- inability to empathize;

- decline in institutional authority;

- overfocusing on psychotherapy;

- tendency to hypochondria (cult of health);

- experiences without a deeper search for meaning;

- identification with celebrities;

- diverting attention only to one's own person;

- identity crisis and a crisis of relationships.

These points summarize what essentially belongs to the concept of cultural narcissism and what is its most common manifestation (Lasch, 1980).

\section{The Character of Cultural Narcissism}

Sociologists understandably ask where the origin of this social dimension of narcissistic behavior is. Lasch, as an American, had a relatively simple and logical theory for the genesis of social narcissism. He recalled, based on Max Weber's reference that throughout the history of the United States the ideal citizen was one who identified himself with the so-called protestant ethics. Protestant ethics was based on the Calvinist theology of predestination. The white people who came in the early phases of colonization from England to the New World, the future United States, were mostly all Calvinist believers and professed faith in their predestination for salvation after death, for which they had been previously designated by God's will. However, recognizing one's predestination is difficult under this theological concept. Practically, it can be done only in one, relatively certain manner, which is identifying one's ability to live a virtuous life, in accordance with biblical moral commandments. Being able to fulfill, in the power of God's grace, the order of a good life, poured into the heart of the destined, gives the believer hope that he is predestined for heaven. Someone incapable of moral quality (an idler, a fool, someone addicted to vice, etc.) can then identify his reprobation, his predestination to eternal damnation.

Although this theist faith has been gradually transformed into deism or has been often denied by the ideology of scientific atheism under the influence of the Enlightenment, protestant ethics has implicitly further determined the civil and social discourse of all white Americans. A law-abiding citizen has continued throughout history to live continuously for the 
Michal PODZIMEK. Problems of narcissism in education: The culture of narcissism as a dangerous global phenomenon for the future

PROBLEMS

OF EDUCATION IN THE $21^{\text {st }}$ CENTURY Vol. 77, No. 4, 2019

492

future of his family and his country, work hard, invest wisely, and for their investment has been able to tighten their belt and above all to submit their will and emotions (desires) to reason. The American citizen has continued to be a type of self-made man. It is then understandable, that this orderly working citizen has accumulated many assets during the period of industrial capitalism, and the USA has become the objectively wealthiest country of the Western world. Through the process getting rich, mostly as a result of their own hard work, however, citizens' aspirations have begun to gradually turn to prosperity as a goal in itself. This, in turn has been progressively redefined to mean prosperity in a purely material sense. Thus, the originally poor, tough and humble citizen, has become a wealthy one, and often, in turn, a hedonist. Rich American society has thus gone through considerable development and contemporary society looks like the underworld of the past (Lasch, 1980, p. 53).

The American economist, Richard Easterlin, formulated the notion in the 1970s that the growth of society's prosperity does not increase the populace's satisfaction with life. This observation, known as the Easterlin paradox, stands at the beginning of the development of the concept of the quality of life (Murgaš, 2009). The analysis of the quality of life incorporates the division of human behavior into two basic forms: hedonism and eudaimonia, first described by Aristotle (1996) in The Nicomachean Ethics. The quality of life, especially in its eudaimonic understanding, is strongly associated with the concept of a good life.

Acquiring wealth has meant a major cultural transformation of capitalism. The American, and eventually also the European citizen, at the latest from the 1970s, has had no intention to be a modest self-made man, but has rather stylized himself as a "happy hooker", who tries to captivate others through his image (Lasch, 1980, p. 64). Pleasure has become his truly desired goal: a fast and pleasant delight, a modern awakening of hedonism. This reversal from efficient diligence in the past to contemporary hedonism, which has been realized dizzyingly fast during the first two post-war generations, also involves resisting all things old as being outdated. This resistance also has its repercussions in the philosophical field of the ideas. Post-war man, overwhelmed by the horrors of the last great ideologies of society (Communism and Nazism), becomes a being existentially stripped of all external certitude, left at the mercy of the general nonsense of the world. Philosophical existentialism, as presented by J. P. Sartre in the postwar period, casts man into an existential void. For example, the Czech philosopher Radim Palouš has expressed this ideological shift, respectively the liberation of man from the mandate of great ideas, as follows: "Subjectivity is embraced here as dropping man into the strangeness of the world. Human freedom is the projection of meaning into an absurd universe" (Palouš, 1990, p. 94).

As a result of this absence of great societal goals, postmodern man has gradually closed up in his mortal finitude, stripped of all metaphysical support in religion (in the original Calvinist theism) or in categorical moral imperatives (the Enlightenment ideal of autonomous morality). This loss of an overall meaning of life goes hand in hand with another phenomenon that causes many problems today, especially in the field of education and people's attitude to work: indifference. Indifference is apathy of a new style (Lipovetsky, 2005, p. 51), stemming from the fact that our society does not recognize any priority, definitive codification or center, but only a ceaseless selection from a chain of equal stimulations (Lipovetsky, 2005, p. 53). This new kind of apathy toward learning anything new is not caused by any distress, but rather by an excess of constantly alternating stimuli, which ultimately causes that the more rights, comforts, possibilities and information society gives us, the less we care about them (Lipovetsky, 2005, p. 53).

As far as education and upbringing is concerned, it is important to realize that postmodern man's radical departure from modernity and its values has caused a new kind of illiteracy during the last two generations. This is not merely a crisis of knowledge or some set of difficulties learning about their own cultural history or about abandoned ideas. This new illiteracy reaches 
deeper, and especially so in the case of elementary knowledge in the exact sciences. Their acquisition is inherently demanding and is linked to the requirement of discipline, patience and tenacious modesty in the process of learning. However, very few young people today are willing to sacrifice their time and will to acquire knowledge in areas such as mathematics, science, the knowledge of another language, etc. If one has not learned the necessary degree of discipline at an early age, he often suffers from a pathological inability to concentrate and to have a deeper interest in serious subjects and questions, which is naturally relevant from the perspective of education and training.

Narcissism has been recognized by the American Psychiatric Association (APA) as an official mental personality in their Diagnostic and Statistical Manual of Mental Disorders (DSM) as a personality disorder since 1968, mentioning similar phenomena and similar pathological manifestations, as professor Lasch in his book on the same topic published 12 years later. The problem, however, is that even though narcissism has been recognized as a personality disorder, individuals suffering from narcissism usually function in normal life in an ordinary way. From this perspective, there is an interesting book by the therapist Heinz Peter Röhr, Narzissmus: The Dem inneren Gefangnis entfliehen (Narcissus, 1999), in which he dedicates his attention not only to the question of the origin and course of narcissism as a disease, but he also outlines the possibilities of overcoming the challenges of narcissism for people with borderline narcissistic disorder, who are living a normal life. He describes narcissism here through the Grimm Brothers' fairy tale, "The Iron" (Röhr, 2018). Similarly, the American Diagnostic and Statistical Manual of Mental Disorders (DSM) admits that narcissism can be found in normally functioning people, as well, therefore, out of its nine symptoms, at least five have to be found for a diagnosis of narcissism:

(1) has a grandiose sense of self-importance (e.g., exaggerates achievements and talents, expects to be recognized as superior without commensurate achievements)

(2) is preoccupied with fantasies of unlimited success, power, brilliance, beauty, or ideal love

(3) believes that he or she is "special" and unique and can only be understood by, or should associate with, other special or high-status people (or institutions)

(4) requires excessive admiration

(5) has a sense of entitlement, i.e., unreasonable expectations of especially favorable treatment or automatic compliance with his or her expectations

(6) is interpersonally exploitative, i.e., takes advantage of others to achieve his or her own ends

(7) lacks empathy; is unwilling to recognize or identify with the feelings and needs of others

(8) is often envious of others or believes that others are envious of him or her

(9) shows arrogant, haughty behaviors or attitudes

However, the problem is even more complicated. In 2010, the Association for Research in Personality discussed whether all of the above-mentioned signs necessarily correspond to narcissistic disorders (Schmeck, Schluter, Foelsch, \& Doering, 2013). Most of the manifestations of this disorder can also be observed in antisocial or obsessive personality (Skodol, Bender, \& Morey, 2014). And finally, the majority of researchers holding a membership in the International Society for the Study of Personality Disorders concluded that narcissistic personality disorder would be kept as a distinct type of disorder, but with four characteristic traits, namely: pathological disposition, a grandiose or on the contrary, vulnerable phenotype; expressivity or, on the contrary, being unable to properly express oneself verbally; and a specific overall structure of personality (Morey \& Stagner, 2012).

Many related research projects which are based on the above-mentioned APA typology of narcissism agree on the fact that narcissism is such a characteristic feature of personality 
Michal PODZIMEK. Problems of narcissism in education: The culture of narcissism as a dangerous global phenomenon for the future

PROBLEMS

OF EDUCATION

IN THE $21^{\text {st }}$ CENTURY Vol. 77, No. 4, 2019

494

which is measurable. This measurability has also become the basis of those research projects, carried out amongst university lecturers in the United States, which are to be mentioned on the following pages. The reason for this is that Narcissistic Personality Disorder can be measured by methods, which detect, above all else, the presence of the following character traits: arrogance, self-centeredness, desire for attention, exploitation, charm, cunning, malice, disdain, revenge, boastfulness, uneasiness, grandiosity, reserve, inaccessibility, insecurity, indifference, anxiety, supremacy, coldness, aggression, day dreaming, shyness, sexual inhibition and others (Paris, 2014).

\section{The Phenomena of Narcissism}

From the above mentioned summary, it is clear that the influence of postmodern man's departure from their past in modernity has created a new, narcissistic way of life. Narcissism is now a social phenomenon, though it was originally diagnosed only as the psychological pathology of individuals. The narcissistic demand for the least possible limitations and, on the contrary, the opening of space for freedom threatened by nothing and by no-one, has become a social phenomenon of a perfectly personified society (Lipovetsky, 2005). This social phenomenon is evident in people from early childhood, and first of all, in addition to their parents, teachers and educators encounter it in their pedagogical work. Teachers are often forced to adapt to the hedonistic demands of the learners, the latter becoming clients who, above all, want to feel comfortable at school.

Besides the deep transformation of society's approach to upbringing and education, social narcissism has first become manifest in the transformation of the functioning of the family. Just as the ideal of the individual in the sense of the above-mentioned self-made man has been abandoned, the model of the so-called traditional family has also been left behind. Of course, the process of deviating from the traditional concept of the family has started much earlier, already in modernity, in connection with the rise of industrial society. The family, which in premodern times spent the time of work, rest and family time primarily in agricultural communal togetherness, in the industrial society has become unprecedentedly dependent on the bureaucratic institutions of the state, such as education, health care, or government control over many areas of the private life of the secularized citizen as if various social institutions had weakened the internal relationships of the family, and imprisoned them in their own hierarchy. On the so-called principle of biopower, on the formerly natural ties, the so-called dictate of normality was superimposed, enforcing conformity. This phenomenon was already elaborated by Michel Foucault in the 1970s, whose work should be summarized here by mentioning only one, albeit poignant thought from his otherwise extensive work:

the new technology that is being established is addressed to a multiplicity of men, not to the extent that they are nothing more than their individual bodies, but to the extent that they form, on the contrary, a global mass that is affected by overall processes characteristic of birth, death, production, illness, and so on. So after a first seizure of power over the body in an individualizing mode, we have a second seizure of power that is not individualizing, but, if you like, massifying (Foucault, 2003, p. 242-3).

Precisely these attempts to create a homogeneous mass, which often accepts the dictatorship of normality as "herd", are particularly noticeable in the weakening of internal family bonds. The current small, nuclear family, often incomplete, for example only a biological mother with one or two children, easily succumbs to the dictate of compliance in the form of advertisement, fashion, and social trends. An important American sociologist, Daniel Bell, who 
Michal PODZIMEK. Problems of narcissism in education: The culture of narcissism as a dangerous global phenomenon for the future

studied changes in behavioral patterns in American society, commented on this in the book The

Cultural Contradictions of Capitalism as follows:

Though at first the changes were primarily in manners, dress, taste, and food habits, sooner or later they began to affect more basic patterns: the structure of authority in the family, the role of children and young adults as independent consumers in the society, the pattern of morals, and the different meanings of achievement in the society (Bell, 1978, p. 69).

And here, narcissism is revealed as a direct product of the modern "happy hooker" hedonism. The natural link between this hedonism and narcissism is consumption, which is the primary propelling force of the society of consumerism. While it is true that the symbiosis of narcissism and hedonism is largely dependent on the particular economic situation of a given society, nevertheless the same applies even to poorer Western economies where the cultural transformation of modern society has resulted in an increase in mass consumption, including the expansion of goods previously considered to be luxury amongst middle and lower classes of society. It is a process within which getting more and more goods is defined as an urgent need (Bell, 1978, p. 64). The contemporary family, as the first social unit for upbringing and education, is therefore an environment in which cultural narcissism finds fertile soil and is firmly embedded.

In addition to this family crisis, there is another important phenomenon: the postmodern transformation of the relationship of man to his own psyche, mental state. "The psychoanalyst is silent, he died, and we all psychoanalyze ourselves in a vicious and impassable circle. Don Juan died and a new, more disturbing figure emerged: Narcissus, enchanted by himself in his throughout transparent chamber" (Lipovetsky, 1983, p. 63; my translation).

Thus, in his book, L'ère du vide, Lipovetsky defines a totally individualized hedonist who completes cultural narcissism by wanting to express his emptiness to the emptiness of others who are like him. And because of the rapid development of communication technologies has made sharing more than easy, the narcissist communicates his opinion to anyone, only for his own narcissistic pleasure, that is, without any ambition to change or improve anything. "In this narcissistic hedonism, the basic value is the person who is the measure of all things, only he matters..." (Lipovetsky, 1983, p. 63).

This pronounced focus on narcissistic self-observation is often manifested precisely through the way in which psychotherapy is currently used. People suffering from cultural narcissism often attend therapies, but often not to analyze and understand the depths of their problems, which would then be solved by them under the guidance of the therapist. The basic intention of people seeking a psychotherapist is often only to learn something new about themselves.

Another identifiable phenomenon of narcissism, related to the previous one, is the explicit disclosure of the subject's existential emptiness, and shutting society out, through seeking the anonymity of the virtual world of the Internet, social networks, shared online gaming communities, or through limiting interactions to the closed world of hobby groups. In them, his narcissism is accepted and mutually shared, as sociologist Richard Sennett describes in detail in his book, The Fall of Public Man. Here he explores the fact that the public space in which people meet and solve social problems together has virtually disappeared, or rather, it has been replaced by a mutual communication of intimate feelings. Current experience from social networks confirms that the most common question that people in contact with each other ask is what they feel or how they feel (Sennett, 1977). The pleasantness of a given experience, or just merely feeling good in itself has become the only measure of reality for the narcissist.

The most visible phenomenon of narcissism, which also causes socio-economic problems in society, is indifference to work as an instrument of personal growth. After the 
Michal PODZIMEK. Problems of narcissism in education: The culture of narcissism as a dangerous global phenomenon for the future

PROBLEMS

OF EDUCATION IN THE $21^{\text {st }}$ CENTURY Vol. 77, No. 4, 2019

496

completion of compulsory education, as edutainment that had to be pleasant for the narcissist and "cool" at the same time, the phenomenon of narcissistic indifference is being transferred by the present, second generation also to the dimension of employment, to work. Being employed is understood by the narcissist mainly at an instrumental level. It is the necessary evil which is needed to make the money as easy and as fast as possible in order to obtain enough funds to experience the narcissistic relationships of leisure-time. Work is perceived by the narcissist as burdensome duty, albeit necessary from a strictly utilitarian perspective: it makes enjoying free time possible. Employment is the necessary evil of the week, preparation for real life at the weekend. In order to make the unpleasant period of the work week more tolerable, the pressure to make work maximally enjoyable is growing in the atmosphere of cultural narcissism. There is a growing demand for flexible working time, and more and more efforts to reduce the rigidity of the organization, to replace uniform and rigorous working patterns with flexible arrangements, and to give preference to communication over coercion (Lipovetsky, 1983, 32). For example, Simon Winlow and Steve Hall's well-known and often-commented research, entitled "Living for the Weekend: Youth Identities in Northeast England," published in Ethnography (2009), claims young respondents do not feel any relationship to the products of their work. Their only profit from their work is money itself, which they want in order to fund their real life. This life is lived only at the weekends. Simon Gottschalk, based on his own research, also describes cultural narcissism in a similar way. He has analyzed some of the hypermodern trends leading to narcissism in his article entitled "Hypermodern Consumption and Megalomania: Superlatives in Commercials" (2009). He discusses such features as acceleration, surveillance, visibility and abundance, and their transformation in the economic, cultural and political spheres, manifested in passive interest in employment (Gottschalk, 2009).

Lipovetsky likewise refers to narcissistic mentality as hypermodernity in Hypermodern Time (Lipovetsky, 2013) as a period which follows the ideals of modern ad absurdum: at the top of the desert of society a sovereign, informed and free man stands, prudently managing his own life (Lipovetsky, 1983, p. 16). The individualization of hypermodern man, narcissistically self-absorbed in himself only, then prevails over all other social aspects, especially interest in work and the public sphere. This creates a kind of zero sociality (Lipovetsky, 1983, p. 19), which is referred to as the second phase of consumerism (Lipovetsky, 1983, p. 26). One of the most visible signs of such behavior is, on the one hand, exaggerated activity towards one's own person, with passivity and indifference to the outside world and its events on the other hand. The individualized person has become a passive observer of public affairs, which he only considers from a distance, often without his own opinion; well-entertained, irresponsible for anything else than his own spacetime, perfectly personalized, condemned to narcissist self-service.

\section{The State of Research on Narcissism}

The phenomena of cultural narcissism described above, which have often overreached the boundaries of what Freud would tolerate as "natural narcissism", are most frequently encountered by those who are responsible for education, regardless of which stage of the educational system they work in. These people often feel helpless in their position of teacher or educator. What the teacher says has ceased to be sacred, it has profaned to the level of what the media say, and the educational system has become a component whose performance is undermined by apathy resulting from a lack of attention and open skepticism towards knowledge (Lipovetsky, 1983, pp. 61-62). This, however, has caused severe learning difficulties and the above-mentioned new illiteracy in the last two generations. It is therefore appropriate to point out where and by what methods narcissism is already studied in the field of education. The question that will now be of interest to us is how the narcissistic tendencies in the present generation of younger and senior students are specifically expressed, and by what methods they can be measured. The possibility 
to detect the rough level of narcissism in specific school groups seems particularly important for a pedagogue, who wants to better orientate in this environment affected by narcissistic disorder.

The issue of measuring the level of narcissism in school groups has been tackled since 2003 by just a few research teams in the US, led by psychologist W. Keith Campbell, professor of psychology at the University of Georgia. Professor Campbell with his colleagues (Rudich, Sedikides, Foster, Goodie and others) worked between 2002 and 2008 on investigating the rate of narcissism amongst their high school and college students. Thus, their respondents were mainly students, answering as a part of their school duties.

Campbell's definition of contemporary narcissism does not differ from the definitions above. The rate of narcissism is determined here through the respondent's perception of their own personality. A narcissistic respondent is, to a measurable extent, entertains a belief in their own greatness, a result of their exaggerated ideas of their attractiveness and uniqueness.

In terms of self-regulatory strategies, empirical research demonstrates that narcissists use both intrapsychic and interpersonal strategies to maintain their positive self-views. On the intrapsychic side, narcissists fantasize about fame and strategically attribute responsibility for their own success to abilities. On the interpersonal side, narcissists differentially brag and draw attention to the self, and strive to compete with and dominate others. Narcissists also desire to associate with high-status others in order to gain esteem. Not surprisingly, narcissists shift the blame for failures onto colleagues or evaluators. In the simplest terms, one can think of narcissists as individuals for whom enhancing the positivity of the self (specifically, to achieve status and esteem) is overwhelmingly important. Much of their psychological and social lives is directed toward this goal. In the present research, we look at decision making as one of the domains of narcissists' behavior that may be differentially distorted by the striving for status and esteem. One might suspect that narcissists have a particular long-term interest in making reasonable and measured decisions, based on the causal reasoning: good decisions. Success status and esteem, and the fact that status and esteem have heightened salience for narcissists. However, we suspected that narcissists' decisions may be undermined by their short-term interest in maintaining an inflated self-image. Narcissists' grandiose self-views may preclude the realistic appraisal of one's likelihood of success needed for successful decisions, resulting in overconfidence and risk-taking (Campbell, Glori, \& Foster, 2004, p. 298).

Campbell, Glori and Forster have published their research on self-confidence in the current generation of young people in an article entitled "Narcissism, Confidence, and Risk Attitude" (2004) the Journal of Behavioral Decision Making. They established a scale of narcissism ranging from non-narcissists on one end to narcissists on the other.

The first of their three studies was based on the answers of 104 university students from Georgia around the age of 18. They completed an electronic questionnaire in three computerized classrooms, and the completed form was perceived by the respondents as a part of their normal study duties in their current course. The questionnaire was composed of two types of questions: knowledge questions, and questions focusing on respondents' evaluation of their self-confidence in their response to the knowledge questions, in other words, confidence assessment. For example of one of the 150 similar knowledge questions, randomly selected from about 300 general knowledge questions: Who was the first ruler in the Holy Roman Empire? Possible answers: a) Charlemange or b) Zeus? After answering the question, the supplementary question follows: If you answered a) Charlemange, how confident are you that the answer is correct? The respondent then checked one of the seven options (a to g), expressing in percent their confidence in the correctness of their response: a) $50-52 \%$ b) $53-60 \%$ c) $61-$ $70 \%$ d) $71-80 \%$ e) $81-90 \%$ f) $91-97 \%$ g) $98-100 \%$. The results of this research have shown that respondents mostly believe in themselves more than their factual knowledge would warrant. This has confirmed the Campbell team's hypothesis that narcissists believe in themselves more than non-narcissists, although narcissist's actual responses are often quite wrong. This research 
Michal PODZIMEK. Problems of narcissism in education: The culture of narcissism as a dangerous global phenomenon for the future

PROBLEMS

OF EDUCATION

IN THE $21^{\text {st }}$ CENTURY Vol. 77, No. 4, 2019

498

has therefore demonstrated that the rate of narcissism is directly proportional to the excess of self-confidence.

The second one of these three research papers focuses on the extent to which a narcissist is able to take risks. The study is based on the answers of 97 respondents, similar to those in the first study. The study's method of ascertaining respondents' willingness to take risks was based on the strategy that after answering 101 knowledge questions, respondents were given the opportunity to choose or bet on another answer. The conclusion of the study has shown that narcissists are more able to take a risk and gamble - they bet and guess more often.

The third of these three studies had the highest number of participants, namely 607 respondents. The study has focused on the relationship between self-confidence, self-beliefs and self-presentation in risky situations. The aim has been to verify the hypothesis whether a narcissist, in his exaggerated self-esteem and feeling of exceptionalness, brings so much positive belief into a risky situation that in the end they often increase their chances of success. And if a narcissist fails on the ground of facts, are they able to keep their faith in themselves in the face of objective failure. Campbell's team has found that in such cases narcissistically-oriented individuals use the so-called top-down strategy. They seem to repeat to themselves that they are good and great, and therefore they cannot fail at the task. Because of this internal narcissistic strategy, they remain proud and self-confident even when factually their performance is low or truly bad.

The study, which again asked participants to do knowledge tasks, was accompanied by three questions for the respondents (one before and two after the assignment):

A: How does the respondent evaluate their expectation of success at the task before doing it?

B: How does the respondent rate their success after the task?

$\mathrm{C}$ : What does the respondent think about their success in the future with the same or similar assignment?

The evaluation of individual questions was expressed on a scale from 1 (the lowest) to 10 (the highest). The result of this study's assessment has found that narcissists not only uncritically assume that they would certainly succeed at the next similar task, but also that they have been successful at it (often unrelated to the actual outcome) and that they will be much more successful in the future. This has confirmed the original hypothesis that narcissists often consider their abilities to be great completely contrary to the external reality and even if the exact opposite is true. In addition, their future performance expectations have been heavily influenced by their inflated performance estimates performed prior to the commencement of the task (Campbell, Glori, \& Foster, 2004).

In their summary of these published studies, they have concluded that narcissists are influenced in their own decision-making: with both too much self-assurance and willingness to take a chance, especially where success depends not primarily on knowledge or skill, but on taking a risk and a bet. Even though they have lost a lot of points because of their riskiness, they have still judged their performances according to their expectations and not according to external reality. In addition, it has been shown that a narcissistic individual can, due to his uncritical optimism, self-love and absence of fear of failure or depression, draw emotional benefits from remaining in such an emotional state. The authors have thus confirmed the results of older case studies on narcissism and they confirmed the hypothesis that narcissists are in fact generally happier than others as they have higher self-esteem and suffer less depression and anxiety (Watson \& Biderman, 1994). A different team of Campbell, composed of Campbell, Rudich, and Sedikides, has published another interesting study under the title "Narcissism, SelfEsteem, and the Positivity of Self-Views: Two Portraits of Self-Love" in the journal Personality and Social Psychology Bulletin.

The last relevant study, this time in the field of narcissism on social networks, was also 
executed under Campbell's lead, this time with Miller and Buffanri. Their results were published in 2008 under the title "Narcissism and Social Networking Web Sites." Their research shows that narcissists on social networks, especially on Facebook, present much greater self-esteem than they really have. It shows that even though narcissists have lower self-esteem in the real world, they are more creative in online activities and can do whatever it takes for better selfpresentation and an improved online image. A typical feature of narcissistic behavior is thus the exaggeration of information about one's own person and showing off.

Professor Campbell, together with his colleague, San Diego psychologist Jean M. Twenge, has also published the results of some of the above-mentioned studies on cultural narcissism in their monograph, The Narcissism Epidemic, which, although is aimed more at the general public than specialist researchers aptly summarizes and discusses the results of these interesting empirical studies that testify about the state of narcissism in Western society:

Understanding the narcissism epidemic is important because its long-term consequences are destructive to society. American culture's focus on self-admiration has caused a flight from reality to the land of grandiose fantasy. We have phony rich people (with interest-only mortgages and piles of debt), phony beauty (with plastic surgery and cosmetic procedures), phony athletes (with performance-enhancing drugs), phony celebrities (via reality TV and YouTube), phony genius students (with grade inflation), a phony national economy (with \$11 trillion of government debt), phony feelings of being special among children (with parenting and education focused on selfesteem), and phony friends (with the social networking explosion). All this fantasy might feel good, but, unfortunately, reality always wins. The mortgage meltdown and the resulting financial crisis are just one demonstration of how inflated desires eventually crash to earth (Twenge \& Campbell, 2009, p. 6).

The book's authors then describe the trend of cultural narcissism, which is still on the rise, affecting the values of an increasing number of people who are trapped in this pitfall of the social trend. In the authors' opinion, the first area where the trend of narcissism is increasingly manifested is the area of education. Parents less and less instill traditional western values, such as freedom, equality and hard work in their children. Instead, in this type of family upbringing, the cult of the child is growing; of the child who wants to be and has to be admired, and who has to be raised in the faith that he can do anything for his self-development. Parents who are themselves affected by narcissism thus pass on narcissism to the next generation.

The second area where narcissism manifests and causes destruction is the area of the uncritical admiration of celebrities. Modern celebrities often earned their fame with hard fight and tenacious, continuous work. Today's celebrities are rather "made celebrities," such as actors, or people interesting for the media, often eccentric, whom Twenge calls "Superspreaders". But they often spread only superficiality and arrogance. One of the classic examples of how these celebrities influence the lives of their narcissistic admirers is that there is the growing fashion among young people to employ their very own paparazzi to follow them in their private lives. These privacy shots are then narcissistically shared on social networks, and everyone can feel like a celebrity at least in the circle of their acquaintances. In addition, these people have a growing desire for luxury, to which ultimately every admirer has the right, as well as having the right to behave only according to their own ideas, similarly to their admired celebrities.

The third area in which narcissism is increasingly visible is a trend that penetrates into all areas of life, including science, is often expressed by the phrase "You have to be hot!" It is a certain social obsession with the cult of physical beauty. It is taken to extremes by the over use of plastic surgery, fitness clubs, etc. The narcissist "metrosexual" is thus born, one who always wants to be luxurious, beautiful and dressed in designer clothes according to the latest fashion, in short always "in" and never "out". 
Michal PODZIMEK. Problems of narcissism in education: The culture of narcissism as a dangerous global phenomenon for the future

PROBLEMS

OF EDUCATION IN THE $21^{\text {st }}$ CENTURY Vol. 77 , No. 4, 2019

500

It seems that these trends are strongly related to the issue of increasing consumption and hence also to the preservation of economic growth. The authors of the studies have also pointed out that, although their research only concerns the United States, the same trend is either beginning to be seen or has already been influential for a longer time everywhere in the developed and developing world, even in China, which until recently was a closed culture, to some extent outside the range of Western ideas.

\section{Conclusions}

It is true that so far very few scientists or expert teams have been involved in the research of cultural narcissism in the Euro-Atlantic area; and, if they have, then only at the local or national level. This brief summary of books, articles and professional studies cannot, of course, aim at an exhaustive discussion of all texts discussing the phenomenon. Nevertheless, it is not misleading to claim that cultural narcissism has not yet become a subject as frequently discussed at international expert forums and in academic journals as its influence on human life would warrant. As far as Western Europe is concerned, only a few occasional articles and case studies have been published, such as Severe Personality Disorders, published by Cambridge University Press in 2007. In terms of larger scale publications, only two monographs by Arnold Rothstein, The Narcissistic Pursuit of Perfection (2015), and Joseph H. Berke's Why I Hate You and You Hate Me: The Interplay of Envy, Greed, Jealousy, and Narcissism in Everyday Life (2012) have been published, and those only relatively recently. This contribution is therefore also offered as an invitation for new efforts in this field, for joining forces and for common initiatives in the field of pedagogical research into the culture of narcissism in Europe.

\section{References}

Aristotelés (1996). Etika Nikomachova [Ethics of Nicomach]. Praha: Rezek.

Asper, K. (2009). Opuštěnost a sebeodcizení: nové přistupy $k$ terapii narcistické poruchy osobnosti. [Abandonment and self-alienation: New approaches to the treatment of narcissistic personality disorder]. Praha: Portál.

Bell, D. (1976). The cultural contradictions of capitalism. New York: Basic Books.

Berke, J. H. (2012). Why I hate you and you hate me: the interplay of envy, greed, jealousy, and narcissism in everyday life. New York: Routledge.

Buffardi, L., \& Campbell, W. K. (2008). Narcissism and Social Networking Web Sites. Personality and Social Psychology Bulletin, 34(10), 1303-1314. doi: 10.1177/014616728320061.

Campbell, W. K., Glori, A. S., \& Foster, J. D. (2004). Narcissism, overconfidence, and risk attitude. Journal of Behavioral Decision Making, 17, 297-311. doi: 10.1002/bdm.475.

Foucault, M. (2003). Society must be defended: Lectures at the College de France, 1975-76. New York: Picador.

Freud, S. (1919). Totem and Taboo: Resemblances between the psychic Lives of Savages and Neurotics. New York: Moffat \& Yard and Company.

Fromm, E. (1964). The heart of man: Its genius for good and evil. New York: Harper \& Row.

Gottschalk, S. (2009). Hypermodern consumption and Megalomania: Superlatives in commercials. Journal of Consumer Culture, 9, 307-327. doi: 10.1177/1469540509341749.

Lasch, Ch. (1980). The culture of Narcissism: American life in an age of diminishing expectations. New York: Warner Bros.

Lipovetsky, G. (1983). L'ère du vide: Essais sur l'individualisme contemporain [The era of emptiness. Reflections on contemporary individualism]. Paris: Gallimard.

Lipovetsky, G. (2005). Hypermodern times. Oxford: Polity.

Lyons, K. (2016, March 7). Generation Y: A guide to a much-maligned demographic. Guardian. Retrieved from https://www.theguardian.com/world/2016/mar/07/millennials-generation-y-guide-to-muchmaligned-demographic. 
Michal PODZIMEK. Problems of narcissism in education: The culture of narcissism as a dangerous global phenomenon for the future

PROBLEMS

OF EDUCATION

IN THE $21^{\text {st }}$ CENTURY

Vol. 77, No. 4, 2019

Morey L. C., \& Stagner, B. H. (2012). Narcissistic pathology as core personality dysfunction: Comparing the DSM-IV and the DSM-V proposal for narcissistic personality disorder. Journal of Clinical Psychology: In session, 68 (8), 908-921. doi: 10.1002/jclp.21895.

Murgaš, F. (2009). Kvalita života a jen priestorová diferenciácia vokresoch Slovenska [Spatial distribution of quality of life in Slovakia]. Geografický časopis, 61 (2), 121-138.

Palouš, R. (1990). Světověk, neboli hypotéza o konci novověku, ba o konci celého eurověku a o počátku světověku [The World Age, or the hypothesis about the end of the modern era, and about the end of the whole Eurovision and the beginning of world history]. Praha: Vyšehrad.

Paris, J. (2014). Modernity and narcissistic personality disorder. Personality Disorders: Theory, Research, and Treatment, 5 (2), 220-226. doi 10.1037/a0028580.

Rothstein, A. (1999). The Narcissistic pursuit of perfection. Madison: International Universities Press.

Röhr H. P. (2018). Narzissmus: Dem inneren Gefangnis entfliehen [Narcissism: Escape the inner prison]. Florida: Patmos.

Sennett, R. (1997). The fall of public man. Cambridge: Cambridge University Press.

Stein, J. (2013, May 20). Millenials: The me, me, me generation. Time. Retrieved from https://time. com/247/millennials-the-me-me-me-generation/.

Skodol, A. E., Bender, D. S., \& Morey, L. C. (2014). Narcissistic personality disorder in DSM5. Personality Disorders: Theory, Research, and Treatment, 5(4), 422-427. http://dx.doi. org/10.1037/per0000023.

Schmeck, K., \& Schlüter-Müller, S., Foelsch, P. A., \& Doering, S. (2013). The role of identity in the DSM-5 classification of personality disorders. Child \& Adolescence Psychiatry \& Mental Health, 27 (7), 1-11. doi:10.1186/1753-2000-7-27.

Twenge, J. M., \& Campbell, W. K. (2009). The Narcism epidemic. New York: Simon and Schuster.

Watson, P. J., \& Biderman, M. D. (1994). Narcissistic traits scale: Validity evidence and sex differences in narcissism. Personality and Individual Differences, 16(3), 501-504. doi: 10.1016/01918869(94)90076-0.

Winlow, S., \& Hall, S. (2009). Living for the weekend: Youth identities in northeast England. Ethnography, 10 (1), 91-113. http://dx.doi.org/10.1177/1466138108099588.

Wolfe, T. (1976, August 23). The "me" decade and the third great awakening. New York Magazine. Retrieved from http://nymag.com/news/features/45938/index1.html.

Received: May 07, 2019

Accepted: August 09, 2019

Michal Podzimek

$\mathrm{PhD}$, Assistant Professor, Faculty of Science, Humanities and Education, Technical University of Liberec, Studentská 1402/2, 46117 Liberec, Czech Republic.

E-mail: michal.podzimek@tul.cz

Website: https://kfl.fp.tul.cz 